\title{
Acute shallowing of the anterior chamber
}

\author{
R. MAPSTONE \\ From St Paul's Eye Hospital, Old Hall Street, Liverpool L3 9PF
}

SUMMARY In aging eyes phenylephrine drops have no significant effect on the depth of the anterior chamber, whereas pilocarpine drops produce a significant shallowing. If both drugs are instilled simultaneously, a significantly greater decrease in anterior chamber depth occurs. The effect is seen in normal, glaucomatous, and hypertensive eyes, and in eyes with shallow anterior chambers. It did not occur in eyes that had had an iridectomy. During the course of a positive provocative test an acute reduction in anterior depth occurs which is reversed when the angle opens and pressure returns to normal levels. It is concluded that the depth of the anterior chamber is not a static dimension but that changes can occur which are rapid and transient. The mechanism of shallowing and deepening depends on an increase or a decrease in the pupil block force. It is a necessary consequence too that eyes with nonshallow anterior chambers can get closed-angle glaucoma and that this possibility cannot be detected by a conventional gonioscopic approach.

Throughout adult life the only ocular dimensions that change are anterior chamber depth and volume. ${ }^{1-3}$ The change in depth is continuous and, in emmetropes aged 40 and over, represents a decrease of $0.01 \mathrm{~mm} /$ year. ${ }^{4}$ Such a gradual change is by itself unlikely to initiate an acute anterior segment event (such as closed-angle glaucoma), but it may create an anatomical background within which an acute change may more readily occur. For example, in primary closed-angle glaucoma the initiating event is iridocorneal contact, which is a consequence of a forward bowing of the iris. If-because of a shallow anterior chamber-iris is already close to cornea, the bombé necessary to produce iridocorneal contact is reduced, and closed-angle glaucoma becomes a real possibility. The gradual decrease in anterior chamber depth thus provides a static background within which a more acute change (such as an increase in iris bombé) can operate and is probably one of the reasons why angle closing mechanisms usually operate in later life only.

Because the depth of the anterior chamber changes so slowly, it is generally thought that a sudden decrease cannot occur and play a part in the development of acute glaucoma, ${ }^{3}$ though there are reports that an acute shallowing can occur. ${ }^{6-9}$ There is also evidence that when one eye develops closed-angle glaucoma $92 \%$ of the fellow eyes that get the disease can be selected within 2 months of presentation by doing a pilocarpine-phenylephrine provocative test. ${ }^{10}$

Correspondence to Mr R Mapstone.
This suggests that, at presentation, conditions in the fellow eye are already such that closed-angle glaucoma can be produced, even though $40 \%$ of spontaneous acute attacks occur 5-10 years after presentation. " The fact too that closed-angle glaucoma can occur in eyes with anterior chambers deeper than 2.4 $\mathrm{mm}^{12}$ is difficult to reconcile with the idea that the anterior chamber depth cannot change rapidly.

The purpose of this paper is to report an investigation of the hypothesis that anterior chamber depth is not a static dimension but that it can show rapid, transient change.

\section{Material and methods}

The basic experiment was divided into 3 stages.

Stage 1. At the start intraocular pressure and pupil diameter were measured, gonioscopy was done, and the presence of iridocorneal contact sought in the 4 quadrants. The depth of the anterior chamber was measured with a Jaeger depth micrometer. One drop of the drug (or drugs) was then instilled into the eye. Stage 2. Approximately $1 \frac{1 / 4}{4}$ hours later the measurements and observations made at the start of stage 1 (with the exception of gonioscopy) were repeated. Another drop of the drug or drugs was instilled.

Stage 3. After the lapse of another $1 \frac{1 / 4}{4}$ hours the measurements and observations were recorded again and the experiment was terminated-that is $2 \frac{1 / 2}{2}$ to 3 hours from the start.

The following experiments were done: 
(1) Thirty-four eyes, 10 of which had no significant ocular disease and 24 untreated ocular hypertension, had no drug other than benoxinate hydrochloride instilled. The spontaneous change in depth was measured.

(2) Thirty-nine eyes, 20 of which had no significant ocular disease and 19 untreated ocular hypertension, had phenylephrine $10 \%$ drops instilled at stages 1 and 2 .

(3) Twenty eyes, 5 of which had no significant ocular disease and 15 untreated ocular hypertension, had pilocarpine $2 \%$ drops instilled at stages 1 and 2 .

In the next 4 groups of eyes pilocarpine $2 \%$ drops and phenylephrine $10 \%$ drops were instilled at stages 1 and 2.

(4) Forty-two eyes which had no significant ocular pathology.

(5) Seventeen eyes with treated open-angle glaucoma all of which were having at least pilocarpine drops. These patients were instructed to continue treatment as was their habit, so that all eyes had had pilocarpine instilled within the preceding 4 hours.

(6) Thirty-five eyes with untreated ocular hypertension.

(7) Twenty-two eyes at risk of developing closedangle glaucoma (because the other eye had developed that disease). None of the eyes had ever had spontaneous or induced closed-angle glaucoma.

The next group also had pilocarpine $2 \%$ drops and phenylephrine $10 \%$ drops instilled at stages 1 and 2, and are derived from 10 consecutive fellow eyes that developed a positive provocative test.

(8) Ten fellow eyes had pilocarpine $2 \%$ drops and phenylephrine $10 \%$ drops instilled at stage 1 . If an acute closed-angle glaucoma had developed by stage 2 , the acute attack was terminated with pilocarpine $2 \%$ drops and thymoxamine $1 / 2 \%$ drops, 1 drop of each. If closed-angle glaucoma had not developed by the start of stage 2, another drop of pilocarpine and phenylephrine was instilled. When the acute attack had developed it was terminated with pilocarpine and thymoxamine. Five of the 10 patients also received intravenous acetazolzmide $500 \mathrm{mg}$. The last 2 groups also had pilocarpine $2 \%$ drops and phenylephrine $10 \%$ drops instilled at stages 1 and 2 ; they differ from the other groups because they had had a peripheral iridectomy.

(9) Seventeen eyes which had had spontaneous closed-angle glaucoma and peripheral iridectomy some time previously. All eyes were normotensive and receiving no treatment.

(10) Twenty-one eyes with ocular hypertension secondary to an angle-closing mechanism formed this group. An eye from each patient had been randomly selected for a peripheral iridectomy at some time in the past. The effect of pilocarpine and phenylephrine on the 2 eyes of a patient are compared.
Table 1 The spontaneous change in, and the effect of phenylephrine or pilocarpine upon, anterior chamber depth

\begin{tabular}{lllll}
\hline & $\begin{array}{l}\text { Number } \\
\text { of } \\
\text { eyes }\end{array}$ & $\begin{array}{l}\text { Mean } \\
\text { age } \\
\text { (SEM) }\end{array}$ & $\begin{array}{l}\text { Mean } \\
\text { change } \\
\text { in depth } \\
(\mathrm{mm})\end{array}$ & $\begin{array}{l}\text { Standard } \\
\text { deviation }\end{array}$ \\
\hline Spontaneous change & 34 & $\begin{array}{l}69 \cdot 1 \\
(1.5)\end{array}$ & $+0 \cdot 01$ & $0 \cdot 07$ \\
Phenylephrine & 39 & $\begin{array}{l}72 \cdot 3 \\
(2 \cdot 4)\end{array}$ & -0.03 & $0 \cdot 13$ \\
Pilocarpine & 20 & $\begin{array}{l}68.6 \\
(1.6)\end{array}$ & -0.11 & $0 \cdot 15$ \\
\hline
\end{tabular}

SEM = standard error of mean.

Table 2 The effect of pilocarpine and phenylephrine on the anterior chamber depth in 4 groups of eyes

\begin{tabular}{lllll}
\hline & $\begin{array}{l}\text { Number } \\
\text { of } \\
\text { eyes }\end{array}$ & $\begin{array}{l}\text { Mean } \\
\text { age } \\
(\text { SEM) }\end{array}$ & $\begin{array}{l}\text { Mean } \\
\text { change } \\
\text { in depth } \\
(\mathrm{mm})\end{array}$ & $\begin{array}{l}\text { Standard } \\
\text { deviation }\end{array}$ \\
\hline Normal eyes & 42 & $\begin{array}{l}69 \cdot 3 \\
(1 \cdot 3)\end{array}$ & -0.3 & $0 \cdot 16$ \\
Open-angle glaucoma & 17 & $\begin{array}{l}69 \cdot 5 \\
(2 \cdot 7)\end{array}$ & $-0 \cdot 25$ & $0 \cdot 18$ \\
Ocular hypertension & 35 & $\begin{array}{l}71 \cdot 2 \\
(1 \cdot 5)\end{array}$ & -0.24 & $0 \cdot 11$ \\
Fellow eyes & 22 & $\begin{array}{l}68 \cdot 4 \\
(2 \cdot 3)\end{array}$ & $-0 \cdot 21$ & $0 \cdot 15$ \\
\hline
\end{tabular}

SEM =standard error of mean.

All patients were at least 55 years old, and in the first 6 experiments only the right eye was used.

The statistical tests used were Student's $t$ test and the Kruskal-Wallis 1-way analysis of variance.

\section{Results}

Table 1 records the spontaneous change in, and the result of instilling phenylephrine or pilocarpine upon, anterior chamber depth. Neither the spontaneous change nor the decrease which followed the use of phenylephrine were statistically significant (for spontaneous change $t=0.75, \mathrm{p}>0 \cdot 10$; for phenylephrine $t=1 \cdot 22, p>0 \cdot 10)$. Pilocarpine instillation was followed by a significant decrease in anterior chamber depth $(t=3 \cdot 39, \mathrm{p}<0 \cdot 001)$.

Table 2 records the result of instilling pilocarpine and phenylephrine into 4 groups of eyes. In all 4 there was a highly significant decrease in anterior chamber depth (for normal eyes $t=12.47, p<0.001$; for eyes with open-angle glaucoma $t=5 \cdot 77, \mathrm{p}<0.001$; for eyes with ocular hypertension $t=13 \cdot 25, p<0.001$; for fellow eyes $t=6 \cdot 49, \mathrm{p}<0 \cdot 001)$. The null hypothesis that these eyes developed similar decreases, so that they could be regarded as samples drawn from the same population as regards anterior chamber depth changes, was tested by a Kruskal-Wallis 1-way 
Table 3 The anterior depth change in a positive provocative test and during the resolution of the acute glaucoma

\begin{tabular}{lllll}
\hline & $\begin{array}{l}\text { Number } \\
\text { of } \\
\text { eyes }\end{array}$ & $\begin{array}{l}\text { Mean } \\
\text { age } \\
\text { (SEM) }\end{array}$ & $\begin{array}{l}\text { Mean } \\
\text { change } \\
\text { in depth } \\
(\mathrm{mm})\end{array}$ & $\begin{array}{l}\text { Standard } \\
\text { deviation }\end{array}$ \\
\hline Positive test & 10 & $\begin{array}{l}67 \cdot 3 \\
(2.8)\end{array}$ & -0.3 & 0.12 \\
Resolution of test & - & - & +0.27 & 0.13 \\
\hline
\end{tabular}

SEM $=$ standard error of mean.

Table 4 The effect of pilocarpine and phenylephrine on anterior chamber depth in eyes that have had an iridectomy

\begin{tabular}{lllll}
\hline & $\begin{array}{l}\text { Number } \\
\text { of } \\
\text { eyes }\end{array}$ & $\begin{array}{l}\text { Mean } \\
\text { age } \\
\text { (SEM) }\end{array}$ & $\begin{array}{l}\text { Mean } \\
\text { change } \\
\text { in depth } \\
(\mathbf{m m})\end{array}$ & $\begin{array}{l}\text { Standard } \\
\text { deviation }\end{array}$ \\
\hline $\begin{array}{l}\text { Closed-angle } \\
\text { glaucoma PI }\end{array}$ & 17 & $\begin{array}{l}71 \\
(2 \cdot 2)\end{array}$ & $+0 \cdot 18$ & $0 \cdot 19$ \\
$\begin{array}{l}\text { Ocular hypertension: } \\
\text { eye with PI }\end{array}$ & 21 & $\begin{array}{l}68 \cdot 9 \\
(1.9)\end{array}$ & +0.08 & $0 \cdot 12$ \\
\begin{tabular}{l} 
Eye without PI \\
\hline
\end{tabular} & - & - & -0.2 & $0 \cdot 11$ \\
\hline
\end{tabular}

$\mathrm{SEM}=$ standard error of mean. $\mathrm{PI}=$ peripheral iridectomy .

analysis of variance. The hypothesis was rejected $(\mathrm{H}=14.97, \mathrm{p}<0.001)$.

Table 3 records the change in anterior chamber depth that occurred during an induced attack of closed-angle glaucoma and the change during the resolution of that attack. During the acute attack the anterior chamber depth decreased significantly $(t=9.72, \mathrm{p}<0.001)$. During the resolution of the attack the anterior chamber became significantly deeper $(t=6 \cdot 82, \mathrm{p}<0 \cdot 001)$.

Finally, Table 4 records the response to pilocarpine and phenylephrine in eyes that had had an iridectomy. In eyes with previous closed-angle glaucoma there was a significant increase in chamber depth $(t=3.81, \mathrm{p}<0.01)$. In patients with ocular hypertension who had a randomly selected unilateral iridectomy, the eye with an iridectomy developed a significant increase in depth $(t=2 \cdot 65, \mathrm{p}<0.01)$. The contralateral eye, however, which had not had an iridectomy, developed a significant decrease in depth $(t=5 \cdot 8, \mathrm{p}<0 \cdot 001)$.

\section{Discussion}

In eyes with intact irides pilocarpine and phenylephrine produce a significant decrease in anterior chamber depth (Table 2) but, if an eye has had an iridectomy the shallowing does not occur and the anterior chamber becomes significantly deeper (Table 4). An explanation of the mechanism follows.

The major contribution to pupil block comes from the contraction of the sphincter muscle. ${ }^{13}$ Fig. 1 shows

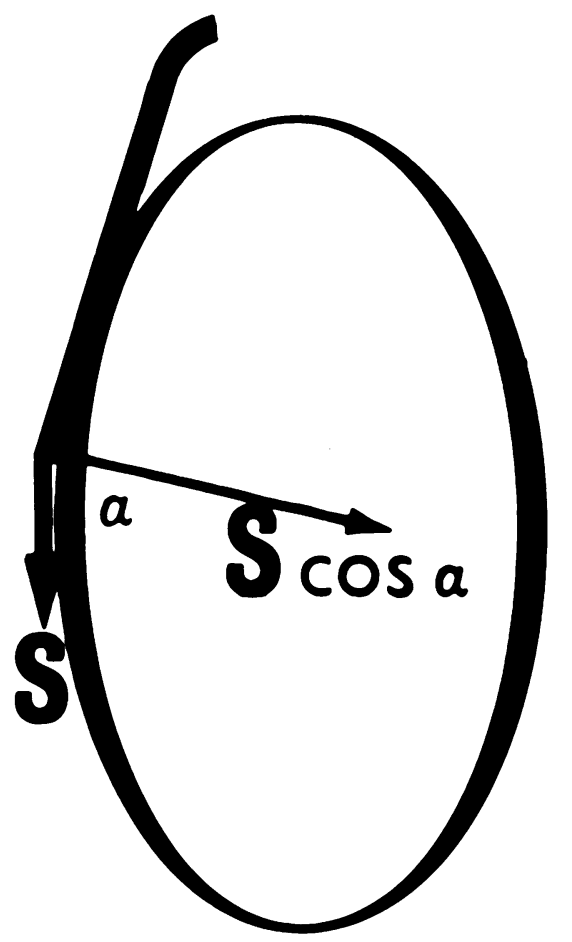

Fig. 1 The major contribution to pupil block comes from the sphincter muscle (S) shown here pulling in a direction at right-angles to the anteroposterior lens axis. The component of this force, pulling the iris back on to the lens is $S \cos \alpha$ (that is pupil block).

the sphincter muscle pulling in a direction at rightangles to the anteroposterior lens axis, and the component of this force, pulling the iris back on to the lens is $\mathrm{S} \cos \alpha$ (that is what pupil block is). The size of the pupil block force can be calculated, ${ }^{13-15}$ and Fig. 2 records the values obtained during the pupillary play of the light reflex. This shows that the sphincter pupil block force is at a maximum when the pupil is middilated, decreasing as the pupil contracts or dilates from that position. One way to increase the pupil block force is to increase the force of sphincter muscle contraction; this is most simply achieved by instilling pilocarpine. But in a normal eye the pupil becomes smaller and the sphincter pupil block force decreases (Fig. 2). If, however, phenylephrine is instilled simultaneously, the sphincter muscle still pulls to a near maximum, but the pupil cannot contract because of the competing pull of the dilator muscle. The result is that the pupil remains at mid-dilatation, the sphincter muscle is contracting strongly, and the sphincter pupil block force is nearly doubled in size. ${ }^{13}$ Pupil block therefore increases, and aqueous escape from posterior to anterior chambers is more difficult. This is 


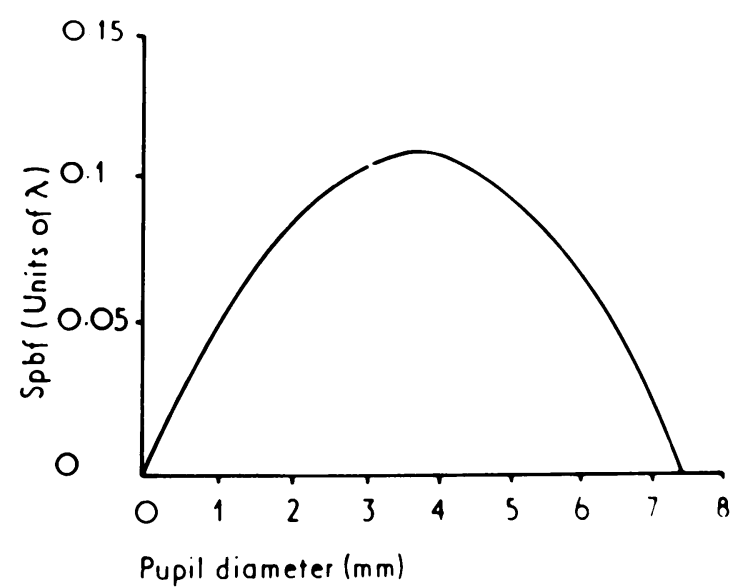

Fig. 2 Variation of the sphincter pupil block force during the pupillary play of the light reflex. $\mathrm{S} \mathrm{pbf}=$ sphincter pupil block force; $\lambda$ =modulus of elasticity of iris stroma.

the rationale of the pilocarpine-phenylephrine provocative test.

The stage shown in Fig. 3 is now reached. Aqueous production (F) continues, although probably at a reduced rate. ${ }^{16}$ Outflow $(C)$ increases (a pilocarpine effect), but aqeuous escape from the posterior chamber is more difficult because of the increased pupil block. The rate of aqueous flow from the posterior to the anterior chamber is now less than the rate of outflow from the anterior chamber to the outside of the eye. A pressure difference develops between the anterior chamber and the rest of the eye, and, because of the tight iris/lens apposition, the iris/lens diaphragm moves forward. Clearly if an eye has had an iridectomy this cannot happen.

A translational displacement of the iris/lens diaphragm will not, however, increase the pupil block force. Fig. 4 shows that an anterior movement does not affect the relationship between the iris and the lens: angle $\alpha$ remains the same. What it does do is to move peripheral iris closer to peripheral cornea, so that the first stage of angle closure-iridocorneal contact-becomes more probable. The situation is represented by a diagram in Fig. 5. Assume that the iris diameter is $12 \mathrm{~mm}$ and that the pupil diameter is 4 $\mathrm{mm}$, then the length of iris from its insertion into the ciliary body to the pupil margin is $4 \mathrm{~mm}$. Next, assume that iridocorneal contact occurs at about $1.5 \mathrm{~mm}$ from the iris root. If the pupillary border of the iris moves forwards by $0.25 \mathrm{~mm}$, the iris base moved by $0.09 \mathrm{~mm}$.

This may not seem much, but, when it is remembered that iridocorneal separation near the limbus in an eye with a narrow angle is about $0.15 \mathrm{~mm}$ or less, it is clear that the acute shallowing demonstrated above moves peripheral iris a substantial part of the way

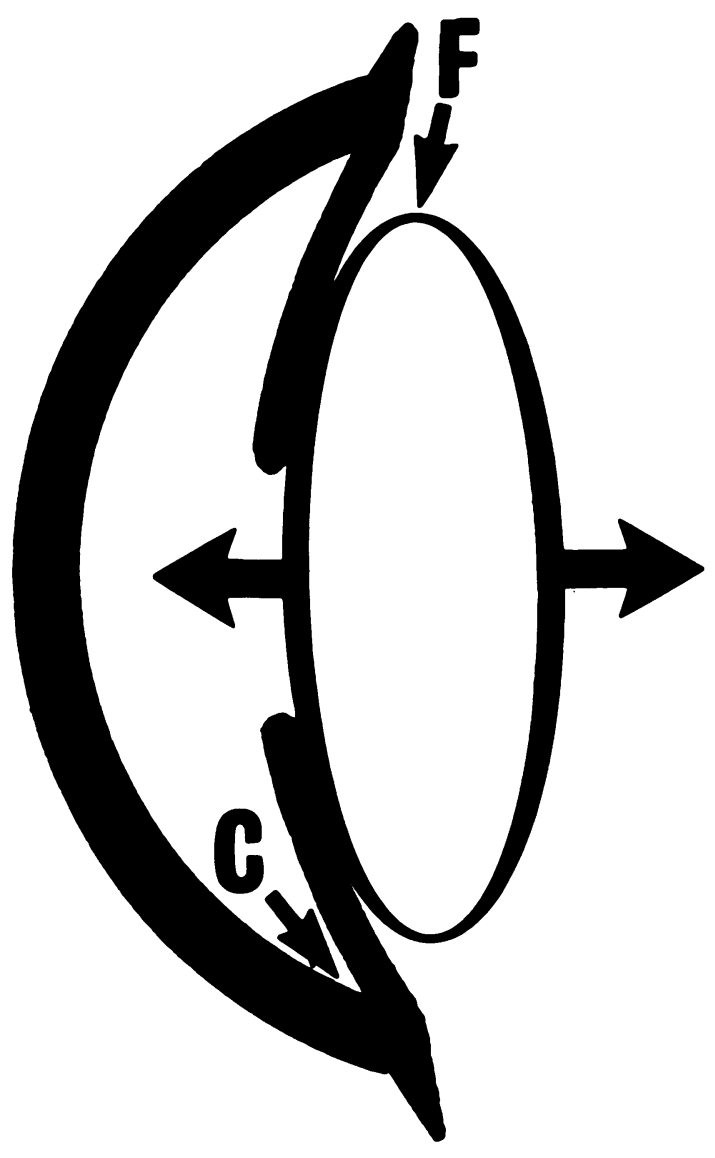

Fig. 3 Pilocarpine and phenylephrine combined increase pupil block and facility of outflow (C) simultaneously. Because of the increase in pupil block aqueous escape from posterior to anterior chambers is more difficult, but, because of the increase in outflow, aqueous movement from anterior chamber to outflow channels is facilitated. At the same time aqueous production (F) continues, and a pressure difference develops between the anterior chamber and the rest of the eye. The result is a translational movement of the iris lens diaphragm towards the cornea and the anterior chamber shallows. Clearly this cannot happen if an eye has had an iridectomy.

towards iridocorneal contact. It is emphasised that the shallowing is a consequence and not a cause of the increase in pupil block force. But that increase in block also produces a forward movement of iris which summates with that resulting from a translational movement of the iris lens diaphragm.

There are therefore 2 reasons why iris can move closer to cornea, and both result from an increase in the pupil block force. Firstly, aqueous escape from posterior to anterior chambers is more difficult and iris bombé increases; secondly, because of the pres- 


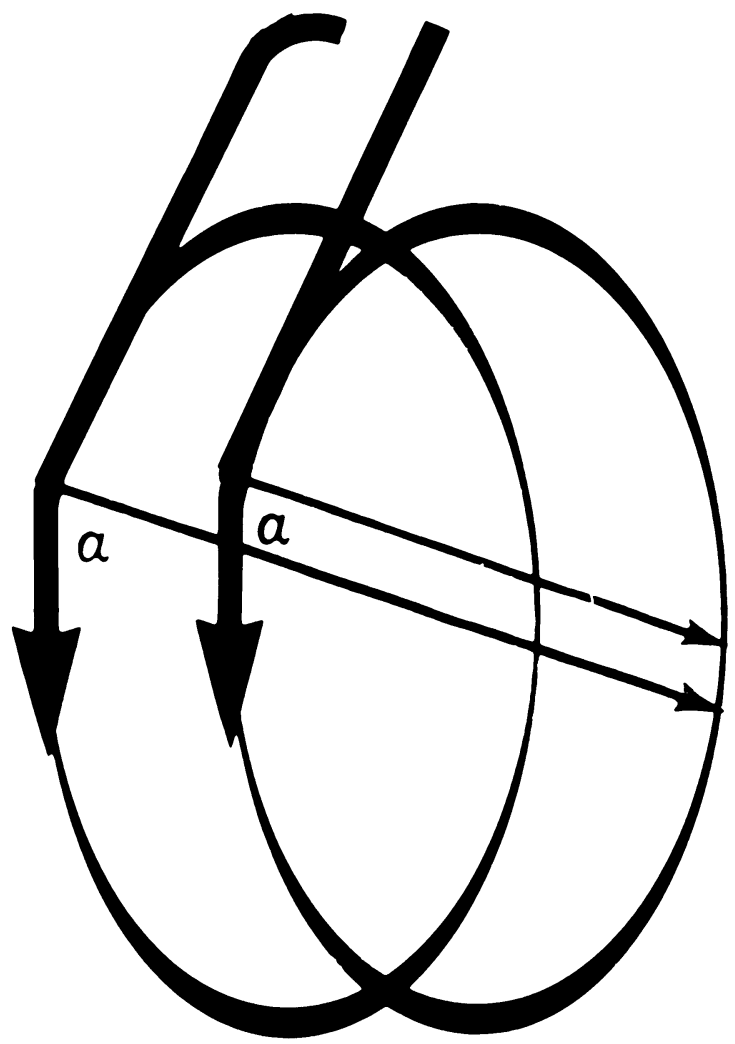

Fig. 4 Diagram to illustrate that an anterior movement of the lens does not change the pupil block force. If the pupil diameter is constant, the posterior component of the sphincter muscle remains the same whatever the position of the lens along the anteroposterior axis. What does change is the position of the iris relative to the cornea.

sure difference created, the iris/lens diaphragm moves forward.

There is one major objection to the pupil block explanation of anterior chamber shallowing. Experimental evidence has been published ${ }^{17-22}$ which shows that pilocarpine alone, in eyes of any age, can produce an anterior-chamber shallowing which is secondary to an increase in lens thickness. It could be argued that the shallowing described above is a consequence of this. This is unlikely to be so in the experiments described because a decrease in depth did not occur in eyes which had had an iridectomy, yet there is no reason to suppose that a change in lens shape did not occur.

Another reason for doubting that a change in lens shape is the explanation comes from the measurements obtained during a positive provocative test (Table 3), during which all 10 eyes developed a decrease in anterior chamber depth. The test was
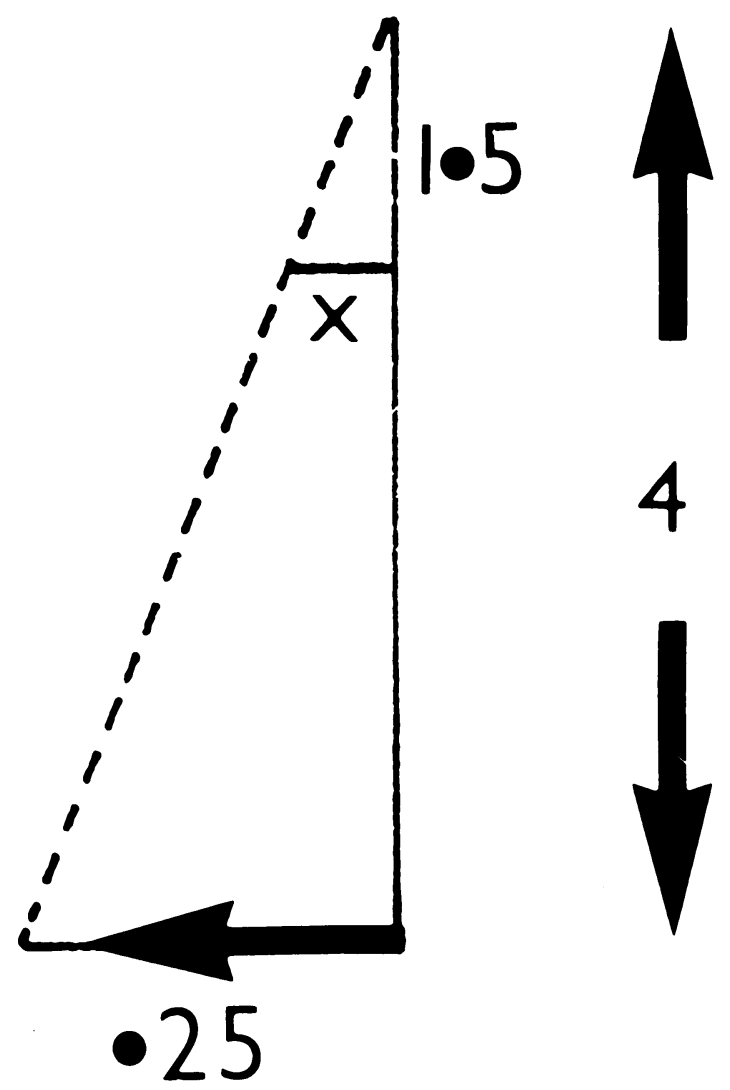

Fig. 5 Diagram to illustrate the effect of anterior chamber shallowing on the position of peripheral iris. Assume a strip of iris to be $4 \mathrm{~mm}$ long (from iris root to pupillary border). Assume too that iridocorneal contact occurs at about $1.5 \mathrm{~mm}$ from the iris root. If the pupillary border of the iris moves forwards by $0.25 \mathrm{~mm}$, then peripheral iris moves closer to cornea by $0.09 \mathrm{~mm}(x / 0 \cdot 25=1 \cdot 5 / 4)$.

terminated in 5 eyes with a combination of acetazolamide, pilocarpine, and thymoxamine; in the other 5 eyes with pilocarpine and thymoxamine alone. Thymoxamine abolishes the effect of phenylephrine, and, because the sphincter muscle is still contracting strongly, the pupil contracts (from a mean of $4.6 \mathrm{~mm}$ to a mean of $2 \cdot 1 \mathrm{~mm}$ ). Because of this the pupil block force decreases (Fig. 2). The pressure difference between the anterior chamber and the rest of the eye (with or without the help of acetazolamide) is removed, and the iris/lens diaphragm springs back to its rest position. If the initial shallowing was the result of a change in lens shape, it would be a necessary consequence that the subsequent deepening occurred because of an opposite change. This is a priori unreasonable. (It is interesting to note too that phenylephrine has no effect on anterior 
chamber depth (Table 1), a reflection of the minimal pupil block that exists in an eye with a widely dilated pupil and of the small contribution that the dilator muscle makes to pupil block.)

Finally, the experimental results have several clinical implications. Firstly, the figures in Table 2 indicate that in a normal population an acute shallowing of the anterior chamber of $0.5 \mathrm{~mm}$ or more might be expected to occur in about $5 \%$ of the population. This means that an eye with an unremarkable chamber depth of, say, $2.5 \mathrm{~mm}^{22}$ can move down to $2.0 \mathrm{~mm}$ or less, into the range where iris bombé can close the angle. The necessary consequence is that acute closed-angle glaucoma can occur in eyes which, when they are examined before or after an acute closedangle glaucoma, have an anterior chamber which is not shallow. There is evidence that this can happen. ${ }^{12}$ Secondly, and because of this, any inference made from doing gonioscopy in an eye with an angle of moderate width is of doubtful value. Finally, if intermittent shallowing can occur and produce intermittent closure, the implications for ocular hypertension and glaucoma are of some clinical significance.

\section{References}

1 Weekers R, Grieten J, Lavergne G. Etude des dimensions de la chambre antérieure de l'oeil humain. Ophthalmologica 1961; 142: 650-62.

2 Weekers R, Luyckx-Bacus J, Weekers JF. Etude ultrasonique des dimensions respectives des segments antérieur et postérieur du globe oculaire dans diverse affections genétiques. In: Ultrasonics in Ophthalmology. Basle: Karger, 1967

3 Sorsby A, Leary G. A longitudinal study of refraction and its components during growth. Medical Research Council Special Report Series no. 309. London: HMSO, 1970.

4 Fontana ST, Brubaker RF. Volume and depth of the anterior chamber in the normal ageing human eye. Arch Ophthalmol 1980; 98: $1803-8$.

5 Rosengren B. The aetiology of acute glaucoma. Am J Ophthalmol 1953; 36: 488-97.

6 Phelps CD. Angle closure glaucoma secondary to ciliary body swelling. Arch Ophthalmol 1974; 92: 287-90.

7 Schwartz AL, Anderson DR. Malignant glaucoma in an eye with no antecedent operation or miotics. Arch Ophthalmol 1975; 93: 379-81.

8 Mensher JH. Anterior chamber depth alteration after retinal photocoagulation. Arch Ophthalmol 1977; 95: 113-6.

9 Gerhard JP, Flament J, Risse JF. Biometric modification of the eyeball in chorioretinal surgery by Lincoff's indentation method. Mod Probl Ophthalmol 1977; 18: 54-6.

10 Mapstone R. The fellow eye. Br J Ophthalmol in press.

11 Lowe RF. Acute angle closure glaucoma. The second eye: an analysis of 200 cases. Br J Ophthalmol 1962; 46: 641-50.

12 Mapstone R. Closed angle glaucoma in eyes with non-shallow anterior chambers. In press.

13 Mapstone R. Closed angle glaucoma. Experimental results. $\mathrm{Br} J$ Ophthalmol 1974; 58: 41-5.

14 Mapstone R. Mechanics of pupil block. Br J Ophthalmol 1968 ; 52: 19-25.

15 Mapstone R. Forces determining pupil size. Exp Eye Res 1970; 10: 47-52.

16 Sears ML, Neufeld AH. Adrenergic modulation of the outflow of aqueous humor. Invest Ophthalmol Visual Sci 1975: 14: 83-6.

17 Abramson DH, Chang S, Coleman J. Pilocarpine therapy in glaucoma: effects on anterior chamber depth and lens thickness in patients receiving long term therapy. Arch Ophthalmol 1976; 94: 914-8.

18 Abramson DH, Coleman DJ, Forbes M, Franzen LA. Pilocarpine effect on the anterior chamber and lens thickness. Arch Ophthalmol 1972; 87: 615-20.

19 Wilkie J, Drance SM, Schulzer M. The effects of miotics on anterior chamber depth. Am J Ophthalmol 1969; 68: 68-83.

20 Poinoosawmy D, Nagasubramanian S, Brown NA. Effect of pilocarpine on visual acuity and on the dimensions of the cornea and anterior chamber. Br J Ophthalmol 1976; 60: 679-90.

21 Francois J, Goes F. Ultrasonographic study of the effect of different miotics on the eye components. Ophthalmologica 1977; 175: 328-38.

22 Lowe RF. Aetiology of the anatomical basis for primary angle closure glaucoma. Br J Ophthalmol 1970; 54: 161-9. 